Brit. 7. Ophthal. ( 1969$)$ 53, I

\title{
Communications
}

\section{Significance of goniohaemorrhage in heterochromic cyclitis}

\author{
I. S. BEGG \\ Sheffield Royal Infirmary
}

A sign, pathognomonic of Fuchs's heterochromic cyclitis, was described by Amsler and Verrey (1946). They observed a filiform haemorrhage in the angle of the anterior chamber which occurred seconds or minutes after paracentesis in each of eighteen cases they examined. This has been confirmed by several authors, including Auvert and Lavat (1952), François (1954), François and Beheyt (1955), Georgiadès (1956), Franceschetti (1955), and Goldberg, Erozan, Duke, and Frost ( I 965). Verrey (quoted by Franceschetti, 1955) and François (1954) observed, by gonioscopic examination carried out immediately after paracentesis, that the blood originated from the canal of Schlemm.

Despite the considerable attention that many authors have paid to the gonioscopic characteristics of heterochromic cyclitis, haemorrhage from the canal of Schlemm induced by gonioscopy has been recorded infrequently (François, 1954; Trantas, 1959a, b). The purpose of this study is to describe haemorrhage in the angle of the anterior chamber induced by gonioscopy, i.e. goniohaemorrhage, as a sign of constant occurrence in heterochromic cyclitis and to discuss its pathogenesis and clinical importance.

\section{Method}

The present study is based on the examination of fourteen cases of heterochromic cyclitis. Eight of these were aphakic; one other had typical bilateral Fuchs's syndrome.

Biomicroscopic examination, recording of applanation tensions prior to gonioscopy, and gonioscopic examination were carried out with the pupils undilated. Gonioscopic examination was performed with a flangeless Goldmann gonioscope and Haag-Streit slit lamp with $\times 25$ magnification; it usually lasted about 2 minutes.

\section{Description of goniohaemorrhage}

Segmental blood filling of the canal of Schlemm was sometimes immediately apparent gonioscopically in the affected eye. In other eyes, a segment, or more commonly segments, of the canal of Schlemm became congested and fusiform during the course of the examination (Plate I). Subsequently, a steady fine leakage of blood into the anterior chamber from the trabecular region was observed (Plates 1, 2, and 3). The haemorrhage was usually evident from several sites in the congested segment, while other blood-filled segments of the canal remained without congestion or haemorrhage. Very occasionally, the entire circumference of the canal was uniformly congested and leaked blood from multiple sites around the circumference. The goniohaemorrhage from the canal of Schlemm could be induced repeatedly on subsequent examinations. 
Angle vasculature, when present, was apparent immediately on applying the gonioscope. After a delay, bleeding from a single radial ciliary vessel was observed in three cases. This haemorrhage was sometimes pulsatile, and so fine that it could easily have escaped attention. It was not observed on a subsequent examination.

\section{Results}

The significant clinical features of the fourteen cases are presented in the Table.

Table Gonioscopic findings in heterochromic cyclitis

\begin{tabular}{|c|c|c|c|c|c|c|c|c|}
\hline \multirow[b]{2}{*}{$\begin{array}{l}\text { Case } \\
\text { No. }\end{array}$} & \multirow[b]{2}{*}{ Eye } & \multirow[b]{2}{*}{$\begin{array}{l}\text { Age } \\
(y r s)\end{array}$} & \multirow[b]{2}{*}{ Iris atrophy } & \multirow{2}{*}{$\begin{array}{l}\text { Intraocular } \\
\text { pressure } \\
\text { (mm. } \mathrm{Hg})\end{array}$} & \multirow{2}{*}{$\begin{array}{l}\text { Blood filling } \\
\text { canal of } \\
\text { Schlemm }\end{array}$} & \multirow[b]{2}{*}{$\begin{array}{l}\text { Radial ciliary } \\
\text { vessels }\end{array}$} & \multicolumn{2}{|c|}{ Site of goniohaemorrhage } \\
\hline & & & & & & & $\begin{array}{l}\text { Canal of } \\
\text { Schlemm }\end{array}$ & $\begin{array}{l}\text { Radial ciliary } \\
\text { vessels }\end{array}$ \\
\hline $\mathbf{I}$ & $\begin{array}{l}\mathrm{R} \\
\mathrm{L}^{*}\end{array}$ & 60 & $\begin{array}{l}\text { Peripheral } \\
+\end{array}$ & $\begin{array}{l}17 \\
20\end{array}$ & $\begin{array}{l}+ \\
+\end{array}$ & $\overline{+}$ & $\begin{array}{l}+ \\
+\end{array}$ & $\bar{t}$ \\
\hline 2 & $\begin{array}{l}\mathrm{R} \\
\mathrm{L}^{*}\end{array}$ & $5^{2}$ & $\overline{+}$ & $\begin{array}{l}34 \\
24\end{array}$ & + & $\overline{+}$ & $\bar{t}$ & $\overline{-}$ \\
\hline 3 & $\begin{array}{l}\mathbf{R} \\
\mathrm{L}^{*}\end{array}$ & 68 & $\overline{+}$ & $\begin{array}{l}16 \\
10\end{array}$ & $\overline{+}$ & $\overline{-}$ & $\bar{t}$ & $\overline{-}$ \\
\hline 4 & $\begin{array}{l}\mathrm{R}^{*} \\
\mathrm{~L}\end{array}$ & 60 & \pm & $\begin{array}{l}20 \\
12\end{array}$ & + & $\begin{array}{l}++ \\
+\end{array}$ & \pm & \pm \\
\hline 5 & $\begin{array}{l}\mathrm{R}^{*} \\
\mathrm{~L}\end{array}$ & 54 & \pm & $\begin{array}{l}18 \\
14 \\
\end{array}$ & $\begin{array}{l}+ \\
+\end{array}$ & \pm+ & \pm & $\overline{-}$ \\
\hline 6 & $\begin{array}{l}\mathrm{R}^{*} \\
\mathrm{~L}^{*}\end{array}$ & 53 & $\begin{array}{l}+ \\
+\end{array}$ & $\begin{array}{l}28 \\
14\end{array}$ & $\begin{array}{l}+ \\
+\end{array}$ & \pm+ & $\begin{array}{l}+ \\
+\end{array}$ & $\overline{-}$ \\
\hline 7 & $\begin{array}{l}\mathbf{R}^{* \dagger} \dagger \\
\mathbf{L}\end{array}$ & 62 & \pm & $\begin{array}{l}8 \\
15 \\
\end{array}$ & \pm & $\stackrel{+}{-}$ & \pm & - \\
\hline 8 & $\begin{array}{l}\mathbf{R} \\
\mathbf{L}^{*}+\end{array}$ & 45 & $\begin{array}{l}\text { Peripheral } \\
+\end{array}$ & $\begin{array}{l}18 \\
18 \\
\end{array}$ & $\begin{array}{l}+ \\
+\end{array}$ & $\stackrel{+}{+}+$ & $\overline{+}$ & $\overline{-}$ \\
\hline 9 & $\begin{array}{l}\mathbf{R} \\
\mathbf{L}^{*} \dagger\end{array}$ & 58 & $\overline{+}$ & $\begin{array}{l}12 \\
18 \\
\end{array}$ & $\begin{array}{l}+ \\
+ \\
\end{array}$ & $\overline{-}$ & $\overline{+}$ & $\overline{-}$ \\
\hline 10 & $\begin{array}{l}\mathbf{R} \\
\mathbf{L}^{*}+\end{array}$ & 66 & $\bar{t}$ & $\begin{array}{l}18 \\
12 \\
\end{array}$ & $\overline{+}$ & $\overline{-}$ & $\overline{+}$ & $\overline{-}$ \\
\hline II & $\begin{array}{l}\mathrm{R}^{*} \dagger \\
\mathrm{L}\end{array}$ & 68 & \pm & $\begin{array}{l}11 \\
26\end{array}$ & $\begin{array}{l}+ \\
+\end{array}$ & $\overline{+}$ & \pm & $\overline{-}$ \\
\hline 12 & $\begin{array}{l}\mathbf{R}^{*} \dagger \\
\mathrm{L}\end{array}$ & 50 & \pm & $\begin{array}{l}15 \\
18 \\
\end{array}$ & $\begin{array}{l}+ \\
+\end{array}$ & $\overline{+}$ & \pm & $\overline{-}$ \\
\hline 13 & $\begin{array}{l}\mathbf{R} \\
\mathbf{L}^{*} \dagger\end{array}$ & 75 & $\begin{array}{l}\text { Peripheral } \\
+\end{array}$ & $\begin{array}{l}17 \\
22 \\
\end{array}$ & $\begin{array}{l}+ \\
+ \\
\end{array}$ & $\overline{+}+$ & $\begin{array}{l}+ \\
+ \\
+\end{array}$ & $\overline{-}$ \\
\hline 14 & $\begin{array}{l}\mathbf{R}^{*} \dagger \\
\mathbf{L}\end{array}$ & 18 & \pm & $\begin{array}{l}25 \\
12\end{array}$ & \pm & \pm & \pm & \pm \\
\hline
\end{tabular}

* Affected † Aphakic

Regurgitation of blood into the canal of Schlemm with subsequent leakage of blood into the anterior chamber was observed gonioscopically in all eyes with heterochromic cyclitis, irrespective of intraocular pressure. The haemorrhage was observed within 2 minutes in all except three cases, where a more prolonged examination of about 3 minutes was necessary to elicit this sign. In five of the eight aphakic eyes, the canal of Schlemm was observed to be filled with blood or congested with subsequent haemorrhage in the area affected by cataract section as well as elsewhere in the angle. 

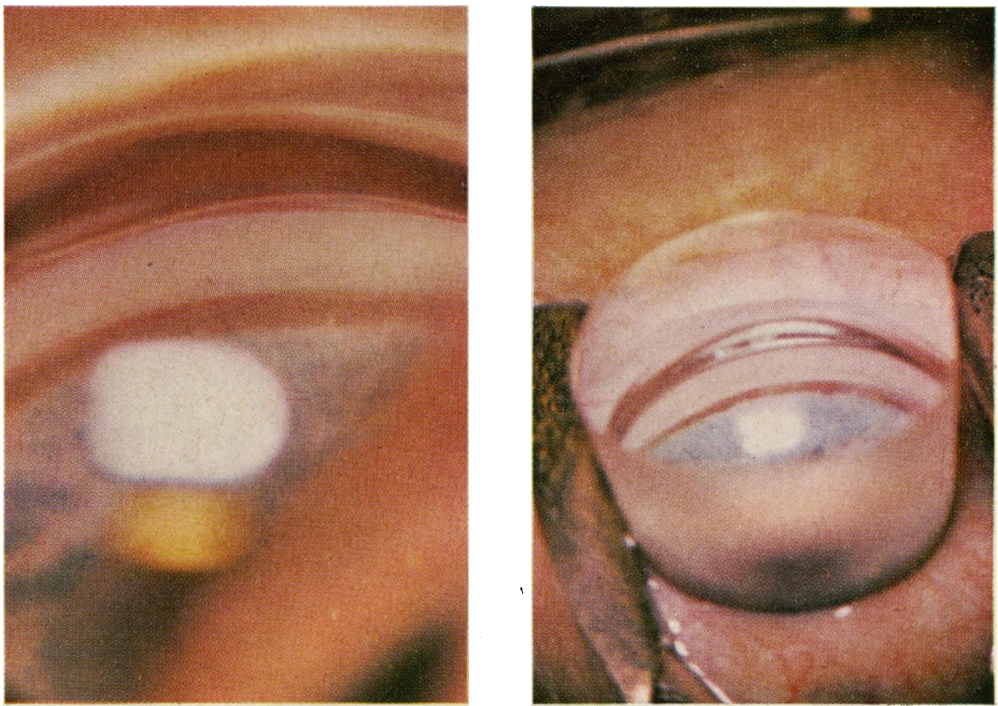

(I)

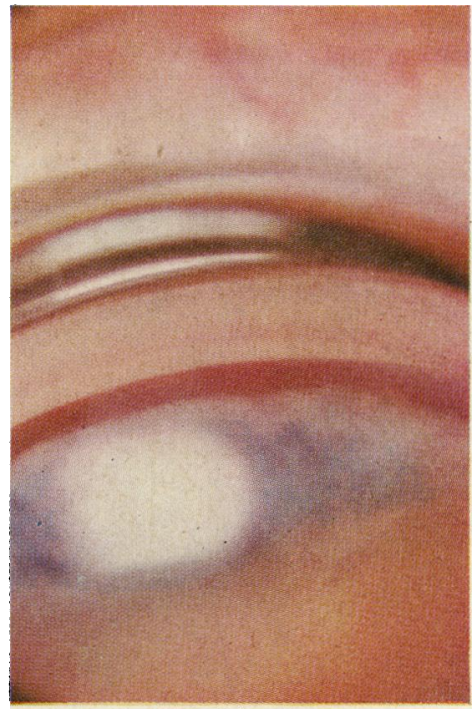

(3)

(1) A congested segment of the canal of Schlemm. A fine leakage of red cells from several sites has formed minute pools of blood at the iris root

(2) Goniohaemorrhage induced by tilting a Barkan lens

(3) At a later stage, the goniohaemorrhage becomes diffused 
In three patients (Cases I, 6, and I3) the haemorrhage was induced in both eyes, all showing a uniform congestion of the entire canal of Schlemm with goniohaemorrhage from multiple points all around the circumference. Of these patients, Case 6 had typical bilateral Fuchs's syndrome and in the others, the eye without cyclitis showed peripheral iris atrophy but was otherwise normal. Only one other patient in the series had peripheral iris atrophy in the eye without cyclitis (Case 8); despite a prolonged and repeated gonioscopic examination, no leakage of blood was observed in this patient, although there was regurgitation of blood into the canal of Schlemm. Of the remaining eleven eyes without cyclitis, blood filling of the canal of Schlemm induced by gonioscopic examination was observed in seven eyes.

In addition to leakage of blood from the canal of Schlemm, goniohaemorrhage from radial ciliary vessels was observed in three affected eyes (Cases I, 4, and I4): in each case from only one radial ciliary vessel. In Case I, the bleeding vessel was the only radial ciliary vessel observed in the angle, while in Cases 4 and I4, the bleeding vessel was one of multiple radial ciliary vessels present. In Case 14, haemorrhage from the canal of Schlemm alone occurred at a subsequent examination. Remnants of mesodermal tissue were present in the affected eye of all three cases; this tissue was not observed with certainty in any other eye.

The angle of the anterior chamber was wide or medium open in all cases, although scattered peripheral anterior synechiae were present in three aphakic eyes (Cases 7, 9, and 14). Multiple radial ciliary vessels, too numerous to count, were present in seven out of fifteen affected eyes (recorded as ++ in the Table). Discrete fine radial ciliary and trabecular vessels numbering from one to approximately five were observed in three affected eyes and in three eyes unaffected by cyclitis (recorded as + in the Table). No radial ciliary and trabecular vessels of either type were observed in five affected eyes although bleeding from the canal of Schlemm was induced in all of them.

It was difficult to distinguish the origin and termination of the multiple radial ciliary vessels. However, in three affected eyes, one vessel was observed to arise with certainty from the circular ciliary vessel. It was common to observe isolated loops or larger segments of the circular ciliary vessel in both affected and healthy eyes. Radial iris vessels were very numerous in the affected eye of one case only (Case 4).

In nine cases, aqueous outflow values, determined by tonography, were available. Bleeding from the canal of Schlemm occurred despite values of less than 0.13 in eight affected eyes. Goniohaemorrhage was not observed in a control series of patients with iris atrophy from other causes, namely chronic simple glaucoma, diabetes, chronic uveitis, and Horner's syndrome.

\section{Discussion}

\section{Blood filling of the canal of Schlemm}

This phenomenon was provoked by gonioscopy in roo per cent. of the affected eyes and in 69 per cent. of eyes unaffected by cyclitis (Table). The incidence of blood filling in normal eyes has been variously reported (Bangerter and Goldmann, 1941 ; François, 1955; Gorin and Posner, 1961). To obtain a greater proportion of patients showing this phenomenon, Hobbs (1950) and Smith (1956) used a modified Goldmann ridged gonioscope. Smith (1956) found that blood filling of the canal of Schlemm decreased with age, which emphasizes the significance of the finding in the present series in which twelve of the fourteen patients were over $5^{0}$ years old. 
Haemorrhage into the trabeculae with subsequent leakage into the anterior chamber

This was induced by gonioscopy in all eyes affected by heterochromic cyclitis and was observed to originate in the canal of Schlemm. This sign has been recorded by François (1954) and Trantas (1959a, b; 196r), who stated that it was very characteristic.

Apart from heterochromic cyclitis, trabecular haemorrhage has been infrequently and briefly recorded in the literature. It has been observed in severe cases of iridocyclitis (Busacca, 1945), in which it is always related to acute ocular hypotony (Kronfeld, 1949). It occurred in less than 20 per cent. of "normal" eyes after total paracentesis and also after severe and prolonged compression of the globe with the Kukan suction dynamometer (Kronfeld, McGarry, and Smith, 1942). Hobbs (1950) observed it in a small proportion of normal and glaucomatous eyes during examination with a ridged gonioscope, and Suson ( 1965 ) in a few aphakic eyes by gonioscopy during suction with a perilimbal cup. Shaffer (1962) published a stereoscopic goniophotograph of haemorrhage into the trabeculae.

\section{Angle vasculature}

Numerous radial ciliary and trabecular vessels have been described in open angles without synechiae (Amsler and Verrey, 1946; François, 1946, 1954; Georgiadès, 1956), but there have been conflicting reports regarding the incidence. This discrepancy could possibly be due to difficulty in assessing the significance of radial ciliary, and trabecular vessels which may occasionally be present in normal eyes (Henkind, 1964). Furthermore, visible vascularization in heterochromic cyclitis sometimes appeared late in the course of gonioscopy (Franceschetti, 1955) or was obscured by thick mesodermal tissue, or, in a narrow angle, became apparent only after lens extraction (Georgiadès, 1959). Franceschetti ( 1955$)$ noted more or less numerous radial and concentric vessels in the trabecular region in five out of fifteen cases and quoted Vannini, who reported increased angle vasculature in three out of fifteen cases examined. The diagnostic value of these angle vessels was emphasized by Georgiadès (r959) and Huber ( $196 \mathrm{r}$ ), who stated that, with or without glaucoma, abnormal vascularization was always present. Hart and Ward (1967) noted such vascularization in all their cases.

The finding of multiple radial ciliary and trabecular vessels in seven out of fourteen cases in the present series agreed more closely with the findings of Franceschetti (1955) and Georgiadès (1959). Despite the fact that a few discrete, fine, radial ciliary, or trabecular vessels were present in another three affected eyes, it was considered that this type of vasculature could not easily be separated from the description of normal angle vasculature (Henkind, I964). Indeed, the same vasculature was present in three eyes unaffected by cyclitis. Therefore, although increased angle vasculature was common, it could not be considered truly diagnostic as distinct from goniohaemorrhage from the canal of Schlemm which occurred in every case.

\section{Pathogenesis of haemorrhage from vessels in the angle}

The goniohaemorrhage which occurred after paracentesis of the anterior chamber in heterochromic cyclitis was considered by Amsler and Verrey (1946) to originate from fragile sclerotic vessels in the angle. This pathogenesis has been reported in many reviews (Makley, ı956; Gorin and Posner, I96ı ; Georgiadès, ı 96r ; Goldberg and others, I965; Sugar, 1965; Duke-Elder and Perkins, 1966; Ward and Hart, 1967).

Consequently, attention has been directed towards pathological changes in iris vessels, readily available from peripheral iridectomy specimens obtained at cataract extraction. 
Hyalinization of the iris stromal arterioles has been reported (François, 1946; Franceschetti, 1955; Georgiadès, 1956, I961), but was an infrequent observation (Goldberg and others, I965) or was not confirmed (Kimura, Hogan, and Thygeson, 1955). Thinning, irregularity, and fragmenting of the iris arteriole walls were reported by Makley (I956), and narrowing of the lumen by Franceschetti (1955). However, in the few descriptions of angle pathology, radial ciliary vessels have not been described (Kimura and others, 1955; Huber, 196r).

In the present series, bleeding from a radial ciliary and trabecular vessel was observed in three patients, the only ones in which marked mesodermal tissue was present in the angle. Mesodermal tissue sometimes associated with increased vascularization has been noted by several authors, but in a small percentage of cases (François, 1954; Franceschetti, I955; Georgiadès, 1959), and the similarity to certain congenital angle anomalies was noted by Vannini (quoted by Georgiadès, 1959). The association of vessel bleeding and embryonic remnants is perhaps significant, as congenital anomalies are more prone to degenerative complications.

\section{Pathogenesis of haemorrhage from the canal of Schlemm}

So much attention has been given to the possibility that goniohaemorrhage following paracentesis might arise from fragile angle vasculature, that the observations of Verrey (quoted by Franceschetti, 1955) and of François (1954) have been overlooked to some extent. By gonioscopic examination after paracentesis of the anterior chamber, they observed that goniohaemorrhage originated from the canal of Schlemm. The pathogenesis has not been discussed.

In the normal eye, regurgitation of blood into the canal of Schlemm can be induced by any procedure which reverses the pressure gradient between the anterior chamber and the episcleral venous plexus, by virtue of the communications between the aqueous outflow channels and the intrascleral and episcleral venous plexuses as described by Ashton (1952) and Dvorak-Theobald (1955). Regurgitation can be achieved by occlusion of the episcleral venous plexus with the rim of the gonioscope (Sugar, 1940; Kronfeld, 1949; Hobbs, 1950; Smith, 1956); by compression of the globe with a Kukan suction dynamometer; or else by paracentesis of the anterior chamber (Kronfeld and others, 1942).

The incidence of blood-filling of the canal of Schlemm and leakage of blood from the trabeculae would appear to depend on the magnitude of pressure difference created by these various procedures (Kronfeld and others, 1942). In the present series, measurements of intraocular pressure were recorded before gonioscopy, and so do not accurately represent the intraocular pressure coincident with goniohaemorrhage. Measurements made after gonioscopy would also fail in this respect and would be subject to an additional error, as it was found that extensive trabecular haemorrhage led to a rise in intraocular pressure.

The greater effectiveness of the rigid Goldmann gonioscope, as compared with the standard instrument, in eliciting regurgitation of blood (Hobbs, 1950; Smith, 1956), and even leakage of blood through the trabeculae (Hobbs, 1950), could possibly be due to a combined mechanism of occlusion of the episcleral venous plexus and compression of the globe, with hypotony following release of compression. Such a mechanism may account for the high incidence of blood filling of the canal of Schlemm in the present series, as the technique of gonioscopy involved tilting of the contact lens rim towards the globe to give a more complete view of the angle, as described by Gorin and Posner (196r). 
It is difficult to correlate goniohaemorrhage from the canal of Schlemm with the pathological descriptions of the angle in heterochromic cyclitis. Definite sclerosis of the trabeculae with marked obliteration of the intertrabecular spaces was described by Huber (196I), and Kimura and others (1955), and was considered by them to be the cause of increased outflow resistance. Trabecular sclerosis and hyalinization, however, are nonspecific changes in pathological specimens and may mask the initial pathology; they occur in eyes with advanced degenerative changes other than glaucoma (Ashton, Brini, and Smith, 1956).

One explanation of goniohaemorrhage from the canal of Schlemm in heterochromic cyclitis could be that an increased pressure in the blood-filled canal of Schlemm causes rupture of the endothelial vacuoles which constitute the "pore structure" of the inner wall of the canal, perhaps facilitated by degenerative changes. The considerable disproportion in size between red blood cells, diameter $7 \cdot 2 \mu$, thickness $2 \cdot 2 \mu$, and the channels between Schlemm's canal and the endothelial vacuoles, diameter $0 \cdot 5^{-1} \cdot 5 \mu$ (Holmberg, I959) or $0.12-0.44 \mu$ (Kayes, 1967), indicates that this tissue forms the principal barrier to the passage of red blood cells from the canal of Schlemm to the anterior chamber.

There is evidence of widespread corneal endothelial changes in heterochromic cyclitis. In the normal eye, a close similarity between corneal endothelium and the endothelium lining the canal of Schlemm has been noted by Speakman (1959). The mesodermal origin of endothelial cells may render them susceptible to pathological changes, as heterochromic cyclitis is regarded by many as one manifestation of a widespread mesodermal defect (Perkins, I96r).

Glaucoma, clinically resembling chronic simple glaucoma, complicates a significant number of cases (François, I 954; Franceschetti, I955; Huber, 1961 ; Sugar, 1965; Lemke, I 966 ; Hart and Ward, I967). Although there is evidence of increased outflow resistance in these patients (Huber, I96 I ; Hart and Ward, 1967), the occurrence of goniohaemorrhage is independent of this. Compared with the reduced incidence of blood filling of the canal of Schlemm in chronic simple glaucoma (Kronfeld and others, 1942; Bangerter and Goldmann, 1941 ; François, 1955; Smith, 1956), when the main site of increased resistance is in the trabeculae (Grant, 1958; and others), the constant occurrence of goniohaemorrhage from the canal of Schlemm in heterochromic cyclitis provokes some speculation.

Reversal of the outflow pressure gradient after paracentesis is more marked than after episcleral venous plexus compression during gonioscopy, yet goniohaemorrhage from the canal of Schlemm occurs in both procedures. A raised deep scleral venous plexus pressure would account for both increased aqueous outflow resistance and goniohaemorrhage. However, the fact that goniohaemorrhage is a constant phenomenon, whereas increased aqueous outflow resistance occurs only in a proportion of cases, would support the view that the underlying defect is in the endothelial meshwork, but is not presumably sclerosis and fibrosis as described by Huber (I96I) and Kimura and others (I955), unless in very degenerate eyes. This view is supported by the finding of normal episcleral venous pressure in glaucomatous and non-glaucomatous eyes with heterochromic cyclitis (Huber, I96I).

\section{Bilateral Fuchs's syndrome}

Franceschetti (1955), who considered that a great number of bilateral cases were not recognized because they showed a heterochromic cyclitis with almost no heterochromia, recorded an incidence of 12.9 per cent. in a series of 62 cases. In the present series there was only one instance of typical bilateral Fuchs's syndrome (Case 6), but three cases 
presented peripheral iris atrophy in the apparently unaffected eye (Cases I, 8, and I3). Not only was bilateral goniohaemorrhage from the canal of Schlemm observed in the typical bilateral Fuchs's syndrome, but also in Cases I and I 3. Despite repeated attempts, Case 8 did not show goniohaemorrhage. The possibility arises, therefore, that Cases I, 8, and 13 represent an atypical form of bilateral Fuchs's syndrome. No consanguinity of the parents was present in these cases.

\section{Clinical significance}

Angle vascularization was considered to be an important diagnostic sign in heterochromic cyclitis by Georgiadès ( 1959 ) and Huber ( $196 \mathrm{I}$ ), especially in bilateral Fuchs's syndrome, although most series, including the present one, record increased angle vascularization in only a proportion of cases. On the other hand, filiform haemorrhage in the angle induced by paracentesis occurred in every case (Amsler and Verrey, 1946) and was considered pathognomonic of heterochromic cyclitis by François (1954). The diagnostic value of this procedure was reported by Auvert and Lavat (1952). The results in the present series demonstrate that gonioscopy is a reliable, safe, and convenient procedure to elicit goniohaemorrhage.

It is probable that minor episodes of intraocular haemorrhage are quite frequent and pass almost unnoticed in eyes affected by heterochromic cyclitis. Hyphaema is a frequent complication of minor trauma in such cases (Becker and Shaffer, 1965). In the present series, three of the eight aphakic patients were prescribed a contact lens. One of them had a past record of unexplained red cells in the anterior chamber. Clumsy manipulation of the contact lens or episcleral venous plexus compression would appear to have been the mechanism. The author would suggest that a haptic contact lens is contraindicated in heterochromic cyclitis as haemosiderosis will inevitably follow recurrent hyphaemata.

In the determination of aqueous outflow using a perilimbal suction cup, a prolonged but temporary rise in intraocular pressure accompanied goniohaemorrhage from the canal of Schlemm. It is important to recognize this complication which invalidates the results. Trabecular haemorrhage may also be responsible for the acute open-angle glaucoma occasionally induced by paracentesis (Verrey, I96I) or cataract extraction (Lemke, I966).

\section{Summary}

Gonioscopy was performed on fourteen cases of heterochromic cyclitis and on a control group with iris atrophy from other causes. In eyes affected by heterochromic cyclitis, goniohaemorrhage occurred from two sites: the canal of Schlemm and the radial ciliary vessels. Goniohaemorrhage was not observed in the control series. Although increased angle vasculature was common, it could not be considered truly diagnostic of heterochromic cyclitis as distinct from haemorrhage from the canal of Schlemm which occurred in every case. The presence of this latter sign in two apparently unaffected eyes showing peripheral iris atrophy would suggest an atypical bilateral Fuchs's syndrome.

The pathogenesis of haemorrhage from these two sites and its relation to glaucoma is discussed, with comments on the clinical significance of goniohaemorrhage.

I am most grateful to Mr. A. Stanworth and Mr. C. A. L. Palmer for permission to publish details of patients under their care. I wish to thank Mr. A. Stanworth for his valuable advice in the preparation of this paper. I am also indebted to Prof. W. S. Foulds, Tennent Institute of Ophthalmology, Western Infirmary, Glasgow, for the photographic facilities, and to the Carnegie Trust for the Universities of Scotland for their generous grant towards the cost of the illustrations. 


\section{References}

AMSLER, M., and VERREY, F. (1946) Ophthalmologica (Basel), III, I 77

ASHTON, N. (1952) Brit. J. Ophthal., 36, 265

$\longrightarrow$, BRINI, A., and SMITII, R. (1956) Ibid., 40, 257

Auvert, B., and lavat, J. (1952) Ann. Oculist. (Paris), 185, 810

BANGERTER, A., and GOLDMAN, H. (1941) Ophthalmologica (Basel), 102, 32 I

BEGKER, B., and SHAFFER, R. N. (1965) "Diagnosis and Therapy of the Glaucomas", 2nd ed. Mosby

St. Louis

busacca, A. (1945) Cited by Gorin and Posner (196r)

DUKE-ELDER, S., and PERKINS, E. s. (1966) "System of Ophthalmology", vol. 9, p. 594. Kimpton

London

DVORAK-THEOBald, G. (1955) Amer. J. Ophthal., 39, No. 4, pt II, p. 65

FRANCESChETTI, A. (1955) Ibid., 39, No. 4, pt II, p. 50

FRANçors, J. (1946) Ann. Oculist. (Paris), 179, 559

(1954) Ibid., 187, 255

(ı55) In "Glaucoma. A Symposium", ed. S. Duke-Elder, pp. ı69-ı6. Blackwello

Oxford

- and BEHEYT, J. (1955) Ann. Oculist. (Paris), 188, 55

GEORGIADÈs, G. (1959) “XVIII Concilium Ophthalmologicum '1958 Belgica. Acta”, vol. 2, p. I 149 (196I) In discussion of Huber (196I), p. 113

GEORGIAdÈs, M. G. (1956) Bull. Soc. franf. Ophtal., 69, 470

GOLDBERG, M. F., EROZAN, Y. S., DUKe, J. R., and FROST, J. K. (1965) Arch. Ophthal. (Chicago), 74, 60 GORIN, G., and POSNER, A. (196r) "Slit-lamp Gonioscopy". Williams and Wilkins, Baltimore GRANT, W. M. (1958) A.M.A. Arch. Ophthal., 60, 523

HART, c. T., and WARD, D. M. (1967) Brit. J. Ophthal., 51, 739

HENKIND, P. (1964) Ibid., 48, 55 I

HOBBS, H. Е. (1950) Ibid., 34,489

holmberg, A. (1959) A.M.A. Arch. Ophthal., 62, 956

HUBER, A. (1961) Ophthalmologica (Basel), 142, 66

KAYES, J. (1967) Invest. Ophthal., 6, 381

Kimura, s. J., hogan, M. J., and thygeson, P. (1955) A.M.A. Arch. Ophthal., 54, 79

KRONFELD, P. C. (1949) Arch. Ophthal. (Chicago), 41, 393

-, MCGARRY, H. I., and SMITh, H. E. (1942) Amer. J. Ophthal., 25, i 63

LEMKE, L. (I966) Ophthalmologica (Basel), 151, 457

MAKLeY, T. A. (1956) Amer. F. Ophthal., 41, 768

PERKINs, E. S. (196I) Trans. ophthal. Soc. U.K., 81, 53

SHAFFER, R. N. (1962) "Stereoscopic Manual of Gonioscopy". Mosby, St. Louis

SMITH, R. (1956) Brit. J. Ophthal., 40, $35^{8}$

SPEAKMAN, J. (1959) Ibid., 43, 129

SUGAR, H. s. (1940) Amer. 7. Ophthal., 23, 853

(1965) Ibid., 60, I

suson, E. B. (1965) Ibid., 59, 783

TRANTAS, N. G. (1959a) Bull. Soc. franc. Ophtal., 72, 73

(1959b) In discussion of Georgiadès (1959), p. I 157

(196I) In discussion of Huber (196I), P. I 15

VERREY, F. (1961) Idem, p. 114

WARD, D. M., and HART, c. T. (1967) Brit. F. Ophthal., 51, 530 